\title{
Effect of scopolamine on response by the rat to environmental change'
}

R. N. LEATON AND R. L. BUCK, DEPARTMENT OF PSYCHOLOGY, DARTMOUTH COLLEGE, Hanover, $N . H$. 03755

Nineteen rats injected with scopolamine and 18 saline injected controls were exposed in a $T$ maze to different colored arms but were prevented from entering the arms by clear Plexiglas partitions. On a later test trial with both arms the same color and with the partitions removed, both groups significantly chose the changed arm. This was interpreted as indicating that the rats injected with scopolamine habituated as well as the controls.

The results of several experiments (e.g., Carlton, 1968; Leaton, $1968 \mathrm{a}, \mathrm{b}$ ) have been interpreted as showing that the attenuation of central acetylcholine activity by injections of scopolamine impairs habituation. These experiments have typically involved a motor response during the initial habituation period, and many of the results could be accounted for by response perseveration tendencies rather than habituation deficits specifically. The present experiment studied the effects of scopolamine on habituation when no overt motor response was allowed during the habituation period. An experiment by Dember (1956) provided the paradigm. He showed that normal rats allowed to visually examine two different colored arms of a $\mathrm{T}$ maze, but not allowed to enter the arms, entered the changed arm of the maze when later allowed to choose between two arms of the same color. This experiment studied the effects of scopolamine on this stimulus change phenomenon.

Method. The experimental procedure was essentially a replication of that followed by Dember. Thirty-seven experimentally naive male albino rats of Sprague-Dawley strain, approximately 90 days old, were divided into two groups to be treated with either .5 $\mathrm{mg} / \mathrm{kg}$ scopolamine hydrobromide $(\mathrm{Sc})$ or an equal volume of normal saline $(\mathrm{Na})$. The Ss were tested in a T maze, the arms of which could be blocked at the choice point by inserting clear Plexiglas partitions. For initial exposure $S$ was placed in the starting alley and allowed to freely explore for $5 \mathrm{~min}$. The Plexiglas partitions were in place allowing $S$ to see into but not enter the arms. The $S$ was then removed from the maze, the Plexiglas partitions were removed, and the color of the arms was changed. After $60 \sec S$ was returned to the starting alley for one test trial. The first arm $S$ entered with all four feet was recorded as its test trial response. For initial exposure the two arms were different colors, black or white. Position of the colors was balanced between the two groups. On the test trial both alleys were the same color, black for half the Ss in each group and white for half. Initial exposure for each $S$ in both groups began $20 \mathrm{~min}$ after the appropriate intraperitoneal injection and the total testing procedure required approximately $7 \mathrm{~min}$.

Results and Discussion. Both groups significantly chose the changed arm on the test trial. Fourteen of the $18 \mathrm{Ss}$ in the $\mathrm{Na}$ group chose the changed arm ( $p=.015$, sign test) and 14 of $19 \mathrm{Ss}$ in the Sc group $(p=.032)$. Assuming that habituation during the initial exposure is critical for this stimulus change effect, it must be concluded that the Sc injected rats habituated as well as the controls. Thus, previous interpretations of habituation deficits following scopolamine injections must be related to the fact of a motor response during exposure and perhaps to a general response perseveration tendency. In the light of some speculations that scopolamine produces memory impairment, it should be pointed out that the rats injected with scopolamine showed a rather subtle memory. Faced with two maze arms the same color, they could remember which arm had been a different color on the previous exposure trial.

The same dose of scopolamine used here has been found previously to be effective with the same age and strain of rats in producing the marked behavioral effects interpreted as habituation deficits (Leaton. 1968b).

\section{REFERENCES}

CARLTON, P. L. Brain-acetylcholine and habituation. In P. B. Bradley and M. Fink (Eds.), Progress in brain research. Vol. 28, New York: Elsevier, 1968.

DEMBER, W. N. Response by the rat to environmental change. J. comp. physiol Psychol, 1956, 49, 93-95.

LEATON, R. N. Effects of scopolamine on exploratory motivated behavior. J. comp. physiol Psychol, 1968a, in press.

LEATON, R. N. Effects of scopolamine and eserine on position discrimination learning with an exploratory incentive. Psychon. Sci., 1968b, in press.

\section{NOTE}

1. This research was supported by Grant HD $01850-03$ from the National Institute of Child Health and Human Development. 